\title{
Implementing healthy food environment policies in New Zealand: nine years of inaction
}

\author{
Sally Mackay ${ }^{1 *}\left(\mathbb{D}\right.$, Sarah Gerritsen ${ }^{1,2}$, Fiona Sing ${ }^{1}$, Stefanie Vandevijvere ${ }^{3}$ and Boyd Swinburn ${ }^{1}$
}

\begin{abstract}
Background: The INFORMAS [International Network for Food and Obesity/Non-communicable Diseases (NCDs) Research, Monitoring and Action Support] Healthy Food Environment Policy Index (Food-EPI) was developed to evaluate the degree of implementation of widely recommended food environment policies by national governments against international best practice, and has been applied in New Zealand in 2014, 2017 and 2020. This paper outlines the 2020 Food-EPI process and compares policy implementation and recommendations with the 2014 and 2017 Food-EPI.

Methods: In March-April 2020, a national panel of over 50 public health experts participated in Food-EPI. Experts rated the extent of implementation of 47 "good practice" policy and infrastructure support indicators compared to international best practice, using an extensive evidence document verified by government officials. Experts then proposed and prioritized concrete actions needed to address the critical implementation gaps identified. Progress on policy implementation and recommendations made over the three Food-EPIs was compared.

Results: In 2020,60\% of the indicators were rated as having "low" or "very little, if any" implementation compared to international benchmarks: less progress than 2017 (47\%) and similar to 2014 (61\%). Of the nine priority actions proposed in 2014, there was only noticeable action on one (Health Star Ratings). The majority of actions were therefore proposed again in 2017 and 2020. In 2020 the proposed actions were broader, reflecting the need for multisectoral action to improve the food environment, and the need for a mandatory approach in all policy areas.

Conclusions: There has been little to no progress in the past three terms of government (9 years) on the implementation of policies and infrastructure support for healthy food environments, with implementation overall regressing between 2017 and 2020. The proposed actions in 2020 have reflected a growing movement to locate nutrition within the wider context of planetary health and with recognition of the social determinants of health and nutrition, resulting in recommendations that will require the involvement of many government entities to overcome the existing policy inertia. The increase in food insecurity due to COVID-19 lockdowns may provide the impetus to stimulate action on food polices.
\end{abstract}

Keywords: Food environments, Government policy, Nutrition, Accountability, INFORMAS, Obesity prevention

*Correspondence: sally.mackay@auckland.ac.nz

${ }^{1}$ Department of Epidemiology and Biostatistics, School of Population Health, University of Auckland, Auckland 1023, New Zealand

Full list of author information is available at the end of the article

\section{Background}

New Zealand's food environments are characterized by highly accessible and heavily promoted energy-dense, often nutrient-poor, food and drinks that contain high levels of salt, saturated fats and sugars $[1,2]$. Food environments are major drivers of unhealthy diets and energy overconsumption [3-5]. Collectively, unhealthy diets are the greatest contributor to the preventable health original author(s) and the source, provide a link to the Creative Commons licence, and indicate if changes were made. The images or other third party material in this article are included in the article's Creative Commons licence, unless indicated otherwise in a credit line to the material. If material is not included in the article's Creative Commons licence and your intended use is not permitted by statutory regulation or exceeds the permitted use, you will need to obtain permission directly from the copyright holder. To view a copy of this licence, visit http://creativecommons.org/licenses/by/4.0/. The Creative Commons Public Domain Dedication waiver (http://creativeco mmons.org/publicdomain/zero/1.0/) applies to the data made available in this article, unless otherwise stated in a credit line to the data. 
burden in New Zealand. High body mass index (BMI) contributes $8.3 \%$ and other dietary risks (such as high salt intake, low fruit and vegetable intake) contribute $8.6 \%$ of disability-adjusted life-years (DALYs) lost [6]. Combined, this is greater than the estimated $9.7 \%$ of health loss from tobacco use $[6,7]$.

New Zealand adults have the third highest rate of obesity [8] and children the second highest prevalence of obesity [9] within Organisation for Economic Co-operation and Development (OECD) and European Union (EU) countries. In 2018 and 2019, 31\% of adults had obesity, up from $27 \%$ in $2006 / 2007$, and one in nine children aged 2-14 years (11\%) had obesity [10]. Adult and child obesity rates were higher for Mãori and Pacific Peoples and for those living in areas of high deprivation [10].

Effective government policies and actions across settings and sectors are essential to increase the healthiness of food environments and to reduce obesity, diet-related noncommunicable diseases (NCDs) and their related inequities [11]. Food policies need to align to achieve common health, environmental, social and economic goals, to improve the overall food system without undermining one part of it [12]. Internationally, some governments have demonstrated leadership and taken action to improve the healthiness of food environments. These can serve as best practice exemplars or benchmarks for other countries. Despite wide recognition of obesity and diet-related NCDs as a major public health issue internationally, the New Zealand government has been slow to improve food environments. This is in part due to the pressure of the food industry on governments $[13,14]$ and other factors such as the challenges of providing robust evidence in emerging policy areas and the competition for resources between prevention efforts and health services delivery $[15,16]$. Non-cohesive, diverse requests from public health advocates to address unhealthy food environments are unhelpful [16], and so an agreed prioritization of policy demands serves as an effective tool when lobbying for change.

The International Network for Food and Obesity/NCDs Research, Monitoring and Action Support (INFORMAS) [3] developed a tool and process, the Healthy Food Environment Policy Index (Food-EPI) [17], to assess the level of implementation of government policies and infrastructure support compared to international best practice for improving food environments and population diets. The Food-EPI tool and process have been through several phases of development, pilot-tested in New Zealand in 2014 [18, 19], and since implemented (or in progress) in 40 low-, middle- and high-income countries. New Zealand is the first country to implement the tool three times, aligned to political electoral cycles in order to stimulate debate.
This paper presents the results of the third Food-EPI study in New Zealand and compares the government's progress on policy and infrastructure support for healthy food environments in 2020 with 2017 and 2014. We also compare the priority actions recommended by experts in 2020 with priorities in 2017 and 2014.

\section{Methods}

The Food-EPI comprises a "policy" component with seven domains on specific aspects of food environments and an "infrastructure support" component with six domains to strengthen obesity and NCD prevention systems. Good practice indicators contained in these domains encompass policies and infrastructure support necessary to improve the healthiness of food environments and to help prevent obesity and diet-related NCDs. The overview and principles of the development of the methods has been described previously [3] and is summarized in Additional file 1. Food-EPI indicators are consistent with proposed international policy options [20-22]. Food-EPI aims to create a common understanding between public health experts to advocate governments on the priorities for policy action.

A mixed-methods design was used to obtain the ratings of the level of implementation of good practice policies and infrastructure support, and to identify and prioritize actions to fill implementation gaps.

\section{Expert panel}

Public health experts from a wide range of organizations were invited to take part in the Food-EPI as part of an expert panel to ensure expertise for all aspects of policy implementation. Experts invited were academics, researchers and practitioners, and those working in public health nongovernmental organizations (including medical associations, professional bodies and service providers) were invited to take part in the Food-EPI. These included participants from the 2014 and 2017 expert panels. If an expert was not able to participate, they were asked to invite a colleague to participate in their place. Government experts (e.g. from different ministries, the Health Promotion Agency and district health boards) were also invited to participate. All participants on the expert panel provided informed consent before taking part in the appraisal. Government experts, acting as observers, were present to provide clarification or additional information but did not participate in the ranking of actions. This was also the case in 2017, but government experts were not part of the expert panel in 2014. 


\section{International best practice exemplars (benchmarks)}

Benchmarks were selected for each of the good practice indicators from the World Cancer Research Fund International NOURISHING framework [22] and obtained from international food policy experts. Some examples of benchmark policies are the front-of-pack warning labelling system in Chile, the regulatory norms defining limits for foods high in certain nutrients in Chile, the sugar industry levy on sugar-sweetened beverages in the United Kingdom, the inclusion of cultural, ethical and environmental perspectives in the Brazilian dietary guidelines, and the nutrient profiling system used to prevent unhealthy food products carrying health claims in Australia and New Zealand. The full list of benchmarks is available in Additional file 2.

\section{Evidence compilation and verification}

For each Food-EPI (2014, 2017, 2020), an evidence document was compiled outlining the current extent of implementation of all 47 good practice policy and infrastructure support indicators (43 in 2014) across 13 domains, as outlined previously [18], for the expert panel to carry out their assessment [23]. Information was compiled from policy documents, websites and budgets retrieved from websites and through Official Information Act requests and personal communication with government officials. The evidence was comprehensively documented and returned to government officials to verify its completeness and accuracy.

\section{Rating implementation progress}

The expert panel rated the level of implementation in New Zealand against each good practice indicator using the evidence document for reference. This was conducted in February and March 2020 using an anonymous online survey (Qualtrics) ahead of the workshop. Each expert gave a rating for each indicator on a Likert scale of 1 to 5 . A rating of 1 meant the expert panel member believed the New Zealand government had implemented the indicator between 0 and $20 \%$ compared to international best practice, and a rating of 5 indicated implementation of between 80 and $100 \%$ compared to best practice. These were compared to the results of the 2017 and 2014 Food-EPI assessments. The 2017 rating process was carried out using an online survey in April and May, while in 2014, two workshops were convened to obtain ratings. This process was changed after 2014 after receiving evaluative feedback from the 2014 expert panel and learning from other Food-EPI processes that had taken place internationally.

\section{Action and prioritization workshops}

At the workshops, the expert panel met to collectively identify the actions required and prioritize these according to their importance and achievability. In 2020, the implementation of the workshops was affected by COVID-19 restrictions on travel and social distancing. One face-to-face workshop was held in Auckland (19 March) and one online workshop was held via Zoom (8 April) to replace the planned face-to-face workshops in Wellington and the South Island. At the face-to-face workshop, participants decided whether an action was required for an indicator, then reviewed the 2017 action and decided whether to keep the 2017 action, revise it or a develop a new action. Due to time restrictions on the part of public health experts during the COVID-19 pandemic, the actions developed at the Auckland faceto-face workshop were presented to participants in the online workshop. Participants discussed the high-priority actions verbally or via the chat feature and revised the action or developed a new action. The action was displayed in the chat feature and a vote was taken to assess whether the majority of experts were in favour.

During the workshops, the proposed actions were identified as higher or lower priority. Following the workshops, the higher-priority actions were ranked by participants from both workshops using an online survey (Qualtrics) sent to all expert panel members a week after the online workshop. Participants were asked to separately prioritize the importance and achievability of each action, for policies and infrastructure support separately. Importance was defined as the relative need, impact, effects on equity, and any other positive or negative effects of the action. Achievability was defined as the relative feasibility, acceptability, affordability and efficiency of the action. Participants were asked to consider "acceptability to government" as pertaining to New Zealand governments in general, not the government of the day.

The results of the 2017 and 2014 Food-EPIs have been reported previously $[18,24]$.

\section{Data analysis}

The mean rating for each indicator was used to determine an overall percentage level of implementation. These ratings were then categorized into "high", "medium", "low" or "very little, if any" levels of implementation based on the following cut points: $>75 \%=$ high; $51-75 \%=$ medium; $26-50 \%=$ low $; \leq 25 \%=$ very little, if any.

For the prioritization of actions, graphs were created to plot importance against achievability. In general, actions rated highest for both importance and achievability were selected as top priorities. A bar graph was created 
to compare the level of implementation of the indicators between 2014, 2017 and 2020. The content of the actions prioritized by the expert panel was compared between 2014, 2017 and 2020.

\section{Results}

\section{Expert panel}

Participation in the 2020 expert panel was lower than in previous years due to the COVID-19 pandemic, with 27 participants completing the online rating. Ten participants attended the face-to-face workshop. The videoconference workshop was attended by 25 independent participants and four government observers. Thirty-one of the 35 workshop participants (independent experts) completed the online ranking of actions ( $89 \%$ response rate). A total of 39 actions were proposed, 22 as higher priority (and subsequently ranked by experts) and 17 as lower priority. Some actions covered more than one indicator, such as the proposed action to develop a longterm, multisectoral national food systems and nutrition strategy.

\section{Ratings and progress}

Figure 1 presents the level of implementation as rated by the expert panel over the three time points. In 2020, three fifths $(59.5 \%)$ of all the indicators were rated as having "low" or "very little, if any" implementation compared with international benchmarks (49.0\% in 2017 and $60.5 \%$ in 2014). In 2020, $15 \%$ of indicators were rated as high implementation, which was similar to 2014 and $2017(14 \%, 15 \%)$. In 2020, two thirds (69.5\%) of the policy indicators and half $(50 \%)$ of the infrastructure indicators were rated as "low" or "very little, if any" implementation. This was similar to 2014 (75\% policy, $48 \%$ infrastructure) and to 2017 for policy (70\%) but different for infrastructure in 2017, which had dipped to a low of $29 \%$ of indicators ranked as low" or "very little, if any" implementation.

Between 2014 and 2020 for the 43 indicators available for each time period, 26 indicators $(60 \%)$ received the same implementation ranking over all three time periods, 11 indicators had an increase in level of implementation and six indicators had a lower rate, with almost all of the progress occurring between 2014 and 2017.

New Zealand has been rated consistently well against international best practice for six indicators, as indicated in Fig. 1. Two relate to food labelling indicators in the policy section and four relate to different infrastructure support indicators: transparency in the development of food policies; public access to nutrition information; regular monitoring of NCD risk factors and health-related inequalities.

There were 20 indicators for which New Zealand was rated consistently poorly against international best practice (low, very little, if any implementation). Most of these were policy indicators (14,70\%), including implementing restrictions on unhealthy food marketing to children; healthy food policies in schools; fiscal policies to support healthy food choices; limiting the density of unhealthy food outlets; food composition targets/standards in out-of-home settings; and ensuring that trade and investment agreements do not negatively affect population nutrition and health. The six infrastructure indicators were related to leadership, evaluation of major programmes, funding for population nutrition promotion and assessing public impacts of food and non-food policies.

The indicators where implementation levels improved over the period 2012 to 2020 were related to the introduction in 2017 of the Advertising Standards Authority (ASA) self-regulatory code restricting marketing of unhealthy food and beverages to children; the Health Star Rating front-of-pack labelling programme in 2014; the introduction of the National Healthy Food and Drink Policy in 2016 for district health boards and government agencies; and the introduction of the Childhood Obesity Plan in 2015. However, the ASA self-regulatory system has been evaluated as ineffective [25], and the Childhood Obesity Plan has not been widely implemented.

The indicators where implementation regressed since 2017 were the regular monitoring of adult and childhood nutrition status and population intake; food composition targets for out-of-home meals; restricting commercial influences on policy development (this regressed as the government strengthened engagement platforms with industry, for example industry pledges as part of the Healthy Kids Industry Pledge); and formalizing a platform for civil society participation in improving food environments.

\section{Actions and priorities}

In 2020, of the 39 actions proposed during the workshops (Additional file 2), eight policy actions and 14 infrastructure support actions were considered of high priority. Some actions covered more than one indicator. The expert panel prioritized 13 for immediate action (Fig. 2) in terms of feasibility and achievability.

The prioritized actions were compared across 2020 and the previous years (reported in previous publications $[18,24])$ (Table 1) with the key theme of the action indicated in italics. Some of the actions were almost identical over the three time periods: restricting marketing to children; food composition targets for sodium and added sugar; and a sugary drinks levy. The action to ensure that food provided in or sold by schools and early childhood education services met dietary guidelines had a similar 


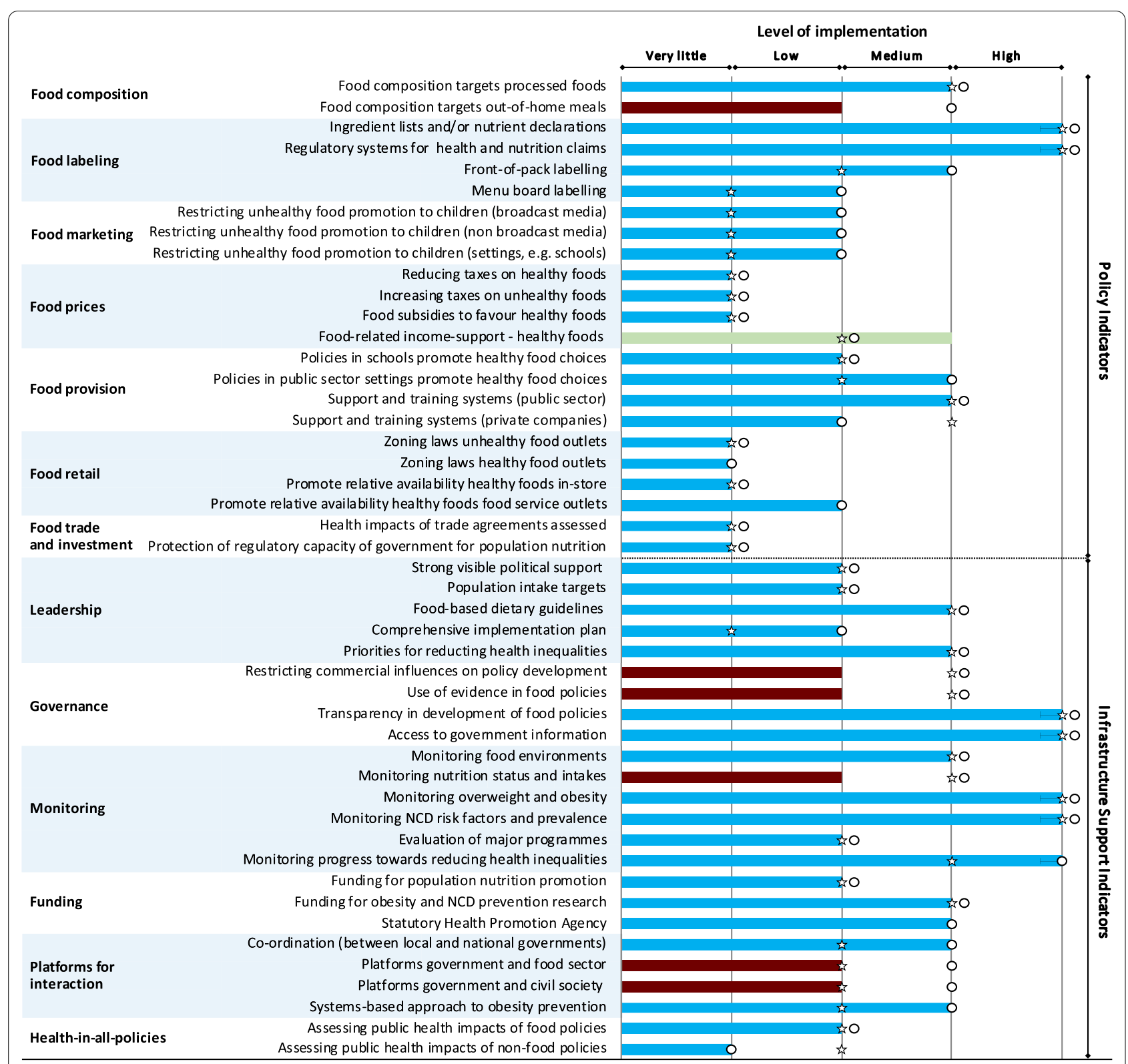

Fig. 1 Level of implementation of food environment policies and infrastructure support by the New Zealand Government in 2020 against international best practice. Star: 2014 Food-EPI ratings; circle: 2017 Food-EPI ratings; Change in level of implementation: Brown: Reduced since 2017; Blue: No change since 2017; Light green: Progress since 2017

theme across years, with the addition of the need for a food policy in 2020.

A few actions proposed by the expert panels changed over time, mostly due to some implementation of the original proposed action. An action plan/strategy was recommended at each Food-EPI, starting with an obesity and NCD prevention plan in 2014. The introduction of the Childhood Obesity Plan in 2015 was reflected in the 2017 recommendation to strengthen this plan. However, this plan was effectively ignored by the next government.
The 2020 action was instead multisectoral in nature, recommending a food systems and nutrition strategy. The government entities with a role in food policy were identified (Table 2). An action related to the Health Star Rating labelling system was prioritized each year. In 2014, this was to implement the Health Star Rating, which occurred in 2014, so in 2017 the action was related to improving the algorithm and mandatory implementation. A review of the Health Star Rating algorithm took place in 2019, so the 2020 action was related to making 


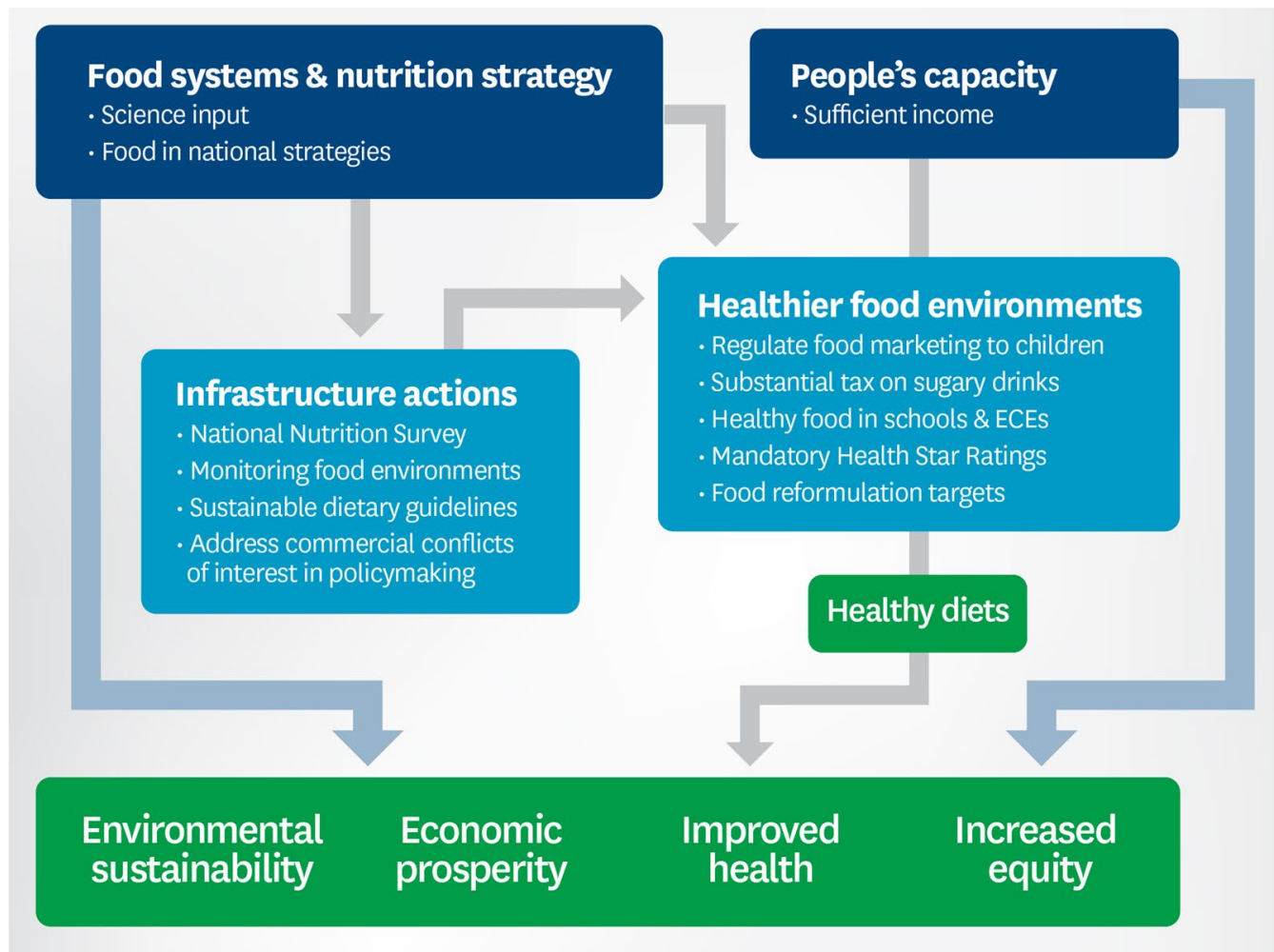

Fig. 2 Recommendations from the expert panel prioritized for immediate action to improve food environments in 2020

the Health Star Rating mandatory and implementing the review recommendations.

Two new actions were introduced in 2017 and one in 2020. In 2017 and 2020 the expert panel recommended actions to implement the Eating and Activity Guidelines introduced in 2015, and to conduct a national nutrition survey (2017, a children's nutrition survey; 2020 a children's and adult nutrition survey). In 2020, the expert panel introduced the importance of ensuring that households have sufficient income as a high-priority action, and an action on conflict of interest procedures when consulting with the food industry.

Some actions were proposed but not prioritized in all years, despite the action not being implemented. In 2014 and 2017, actions related to setting targets to reduce childhood obesity and population intake of salt, sugar and saturated fat were prioritized, but were not considered priority actions in 2020. Increased funding for population nutrition promotion was recognized as an action for each year, but only prioritized for 2014 and 2017.

\section{Discussion}

The 2020 Food-EPI study assessed the New Zealand Government's progress towards international best practice in improving food environments and implementing obesity and diet-related NCD prevention policies, and compared this with earlier similar assessments in 2017 and 2014, finding little or regressed progress over this time period.

\section{Implementation}

The results indicate that overall, almost no progress has been made since the last Food-EPI assessments in 2017 and 2014, and New Zealand has not increased its performance compared with international best practice. For those indicators that had changed since the 2017 assessment, the majority had decreased in levels of implementation (six) with only one area rated as having progressed since 2017.

There was some improvement in the level of implementation due to the introduction of some policies and interventions; however, experts recommended further actions, as implementation has not been sufficient to improve food environments and population diet. There has been no statistically significant change in the prevalence of overweight and obesity in adults or in children 


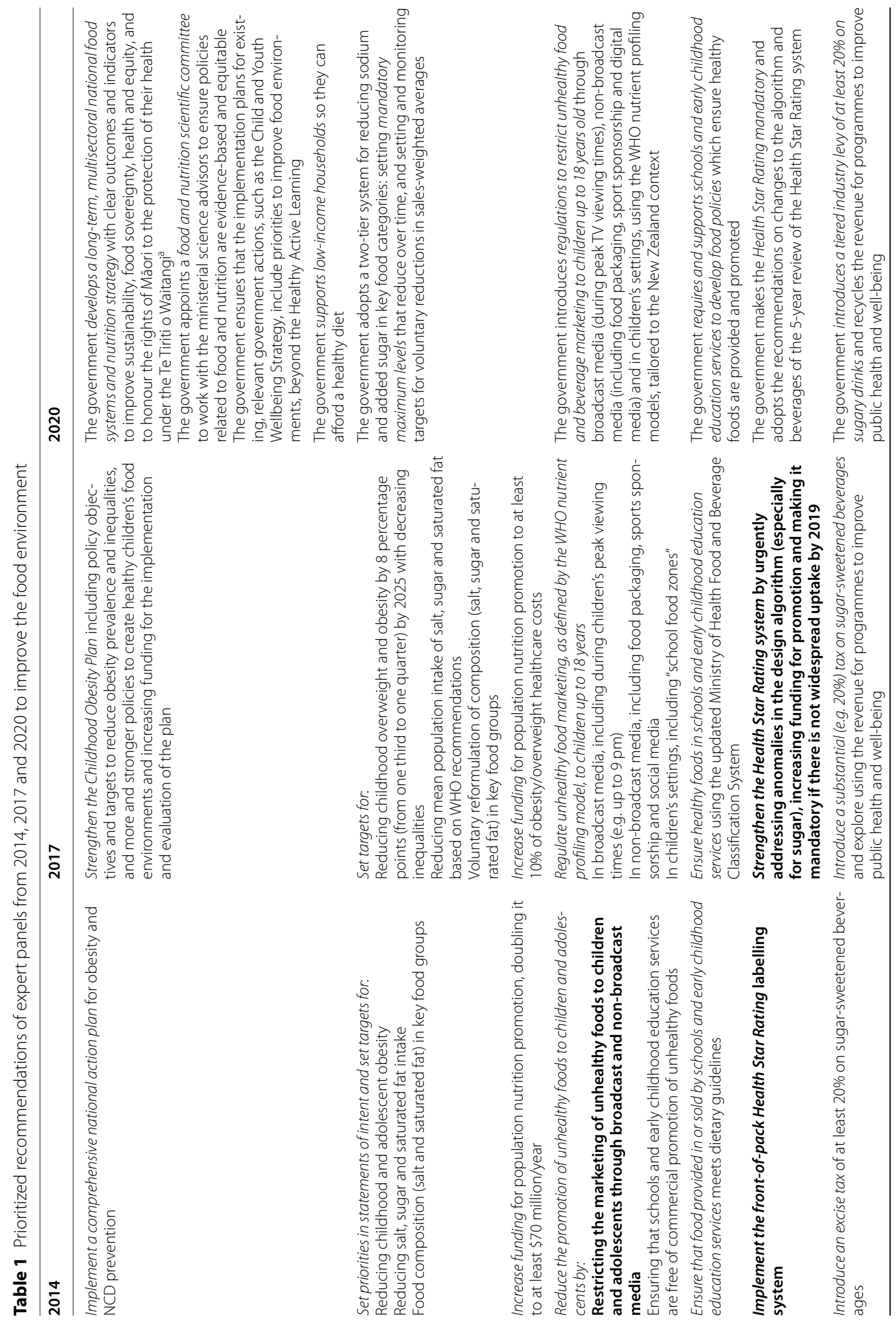




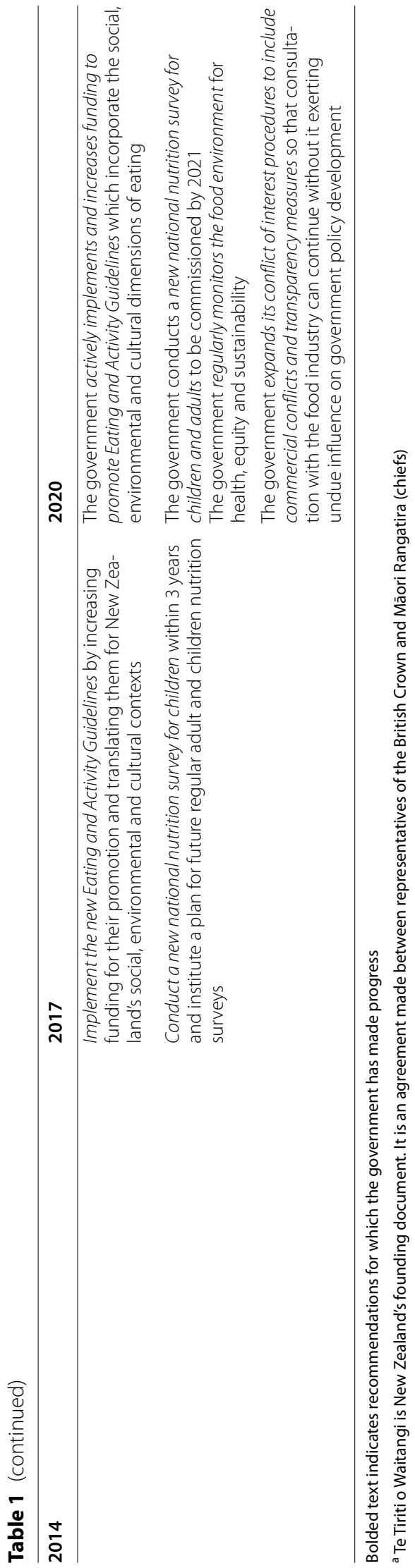


Table 2 Description of government entities with a role in food policy

\section{Government departments}

Ministry of Health

Ministry for Primary Industries

Ministry of Foreign Affairs and Trade

Health Promotion Agency

Ministry for the Environment

Ministry of Business, Innovation and Employment

Food Standards Australia New Zealand

Ministry of Education

Office of the Prime Minister's Chief Science Advisor

Local government

District health boards

The Treasury

Department of Prime Minister and Cabinet

Te Puni Kōkiri-Ministry of Māori Development

Ministry for Pacific Peoples

Ministry of Social Development

Supporting government entities

Health Research Council of New Zealand

Broadcasting Standards Authority

Sport New Zealand

Commerce Commission

National Ethics Advisory Committee

Crown Research Institutes

Health and Disability Commissioner

Office of the Children's Commissioner

Ministry for Culture and Heritage

Ministry of Transport

Department of Corrections

Department of Internal Affairs

\section{Descriptions}

Main policy-making department on diet-related health, nutrition-related health inequalities, planning and funding public health and monitoring the performance of district health boards

Main policy-making department for New Zealand's primary industries, including food. Functions include providing national direction on ensuring the food produced is safe, enabling international market access for New Zealand's primary products, and representing the interests of the New Zealand primary sector in international trade policy and standard-setting forums

Main policy-making department on international food trade, overseas aid (including food aid), overseas agriculture, and the Sustainable Development Goals

Main communications agency to promote health, including healthy diets

Main policy-making department on environmental policy and provides national direction on urban (e.g. food density zoning laws) and rural planning (e.g. land use consents) through national policy statements and national environmental standards. Also focuses on climate change, fresh water, marine, land, waste, soil, air, water, sea quality

Main policy-making department managing food and beverage industry investment, consumer protection, immigration (including migrant workers for food supply chain), business, industrial strategy, employment, energy, science, research and innovation (all with food relevance)

Develops and administers joint Australia and New Zealand food standards; explains food issues e.g. labelling, additives, chemicals; consults with the community about food safety issues; helps food businesses understand the Australia New Zealand Food Standards Code

Main policy-making department on education, skills and curriculum, with role as food educator and food provider

Provides strategic advice across sectors and serves as an accessible conduit between the science community and government

Ensures public services are responsive to the social, economic, environmental and cultural wellbeing needs of their communities, with a particular role in zoning law, district or regional planning, and community food supply initiatives for example

A role to improve, promote and protect the health of people and communities, including planning and delivering services in their area

Overall control of government spending

Overall policy oversight and coordination. Contains the Child Wellbeing and Poverty Reduction Group

Input into major food policies as they relate to Māori

Input into major food policies as they relate to Pacific Peoples

Main policy-making department on welfare and pensions, supporting people and whānau in food poverty

Sets priorities for research and funds research including on food and nutrition

Decides complaints about broadcasters; publishing and research broadcasting standards

Oversees sports sponsorship

Enforces laws that promote competition and protect consumers in New Zealand

Provides ethical advice on issues of national significance in respect of health and disability, including characteristics of a fair food system delivering nutritional outcomes

AgResearch: pastoral, agri-food and agri-technology sector

Plant and Food Research: horticultural, arable, seafood, and food and beverage industries Institute of Environmental Science Research: safeguards people's health, protects the food-based economy, improves the safety of water resources

Works with clinicians, providers and consumers to improve health services including dietary advice and interventions

Advocates for the interests of young people, ensuring the voices of children are heard in policymaking

Funds Broadcasting Standards Authority, NZ On Air and Sport New Zealand

Main policy-making department on transport, with role in supporting infrastructure for food distribution and public transport (including for food workers and customers)

Main department with role as food provider to prisons

Conduit for local and central government 
Table 2 (continued)

\begin{tabular}{ll}
\hline Government departments & Descriptions \\
\hline State Services Commission & $\begin{array}{l}\text { Sets standards for public servants and policy-making, including the management of conflicts of } \\
\text { interest for food policies }\end{array}$ \\
New Zealand Customs Service & $\begin{array}{l}\text { Provides border control and protects the community from potential risks related to food arising } \\
\text { from international trade and travel, as well as collecting duties and taxes on imports to the country }\end{array}$ \\
Ministry of Housing and Urban Development & Main policy-making department on housing, built environment and urban development \\
\hline
\end{tabular}

during the time period covered by the Food-EPI assessments (2012-2020) [10].

\section{Actions}

Reflecting on the changes (or lack of change) over time, the actions proposed in 2014 continued to be high-priority items in 2017 and 2020. The only action which has seen progress over time is the Health Star Rating frontof-pack labelling, with a 5-year review and changes to the algorithm [26], and even with this, a mandatory programme has not been implemented as recommended by experts.

Compared to earlier years, the 2020 actions reflect a growing movement to locate nutrition within the wider context of planetary health, with recognition of the social determinants of health and nutrition, resulting in higherlevel actions proposed that will require the involvement of many government entities. Connecting obesity with climate change and food security will aid progress for all [27]. The expert panel in 2020 was adamant that there needs to be clear leadership and the development of a multisectoral national food systems and nutrition strategy that honours the rights of Māori (New Zealand's indigenous population) under Te Tiriti o Waitangi (New Zealand's founding document) guided by a scientific committee. This recommendation echoes calls from other experts [28] and groups, such as the Food Systems Dialogues [29], Child Poverty Action Group [30] and Eat New Zealand [31], for an overarching strategy, prompted by the United Kingdom Government announcing the establishment of their National Food Strategy in 2020 [32].

The experts expressed concern about the extent of food insecurity in the country and widening health inequities, prioritizing the policy action of ensuring that households receive an adequate income to enable autonomy to make healthy food choices. One in five children live in households experiencing moderate to severe food insecurity [33], and concern about this issue has grown during the COVID-19 crisis [34]. The Child Poverty Reduction Act 2018 [35] requires monitoring of some of the underlying determinants of health, but for substantial change to occur, the Welfare Expert Advisory Group's recommendations require implementation [36]. The disruption of food environments [37], increase in food insecurity due to COVID-19 lockdowns [38] and shift towards an unhealthy dietary pattern [39] may provide the impetus to stimulate action on food polices.

Of continued and growing concern among the FoodEPI expert panel, along with other organizations [40, 41], was the need for another national nutrition survey. Major policy decisions are being made in the absence of evidence about the nutrition status and food consumption patterns of the population. The COVID-19 crisis illustrated the importance of using epidemiological evidence as a foundation for a public health response; this applies equally to the chronic crisis of obesity and unhealthy diets.

The expert panel called for a mandatory approach to be adopted in all policy areas prioritized in 2020, as current voluntary approaches have proven to be ineffective for marketing of unhealthy food to children, Health Star Ratings labelling, healthy food policies in schools and early learning services. Voluntary policies are not enforceable and therefore not implemented or adhered to [42]. Strong government policy is essential to achieve an equitable and sustainable food system [43]. For example, only $23 \%$ of products displayed a Health Star Rating in 2019 [44], and the School Food Environment Review and Support Tool (School-FERST) study found that only $38.5 \%$ of primary schools and $44.8 \%$ of secondary schools had a healthy food policy, with most assessed to be low in strength and comprehensiveness [45].

\section{Implications}

Despite providing the government with direction on the recommended actions to remedy areas where New Zealand's performance is falling short through previous Food-EPI, minimal progress has been made. In the years contributing to the 2014 and 2017 Food-EPI assessments, New Zealand was governed by a centreright minority government, who were replaced in 2017 by a centre-left coalition government. Expectations that a more left-leaning government would implement policies to improve food environments were not met. Driving this policy inertia are three main factors: inadequate political leadership and governance to enact policies; strong opposition to such policies 
by powerful commercial interests; and a lack of public demand for policy action [46]. Further investigation is needed to examine the surrounding determinants of the lack of action for particular indicators, to move towards overcoming this policy inertia. While FoodEPI has stimulated little progress in New Zealand, without independent expert panels measuring the government's performance and comparing it over time, there would be little evidence on which to base calls for policy change and to measure the degree of policy inertia. Progress on recommended actions has occurred in other countries where Food-EPI was undertaken, such as the Australian Government's agreement to the development of a national strategy on obesity [47], a sugar levy introduced in the United Kingdom [48, 49] and legislation in Mexico for front-of-pack warning labels $[50,51]$.

Food-EPI assessed national-level policies and infrastructure action, but future assessments could include local government and district health boards, as they too play a significant role by implementing unique food environment policies at the local level of jurisdiction, such as zoning laws for marketing or incentives to food outlets selling healthier foods. In Canada, "local Food-EPIs" have been successfully conducted in three municipal jurisdictions [52-54]. A separate study benchmarked the commitments of the major food companies in New Zealand related to population nutrition and obesity prevention [55].

The Food-EPI expert panel represents a wide range of organizations from academia, public health units, government policy-makers, nongovernmental organizations and professional organizations. A particular strength of the study is that the evidence document is verified by government officials to ensure it is correct and up to date. Food-EPI has now been completed three times in New Zealand and completed (or in progress) in 40 countries globally, and is therefore a tested and accepted tool for monitoring government progress on improving food environments.

A limitation of the 2020 Food-EPI was that it coincided with the COVID-19 pandemic, which meant many public health experts had limited, if any, time to participate. Despite this, the participating experts were fully engaged and made a valuable contribution. Two changes made to the workshop proved beneficial and are recommended for future Food-EPI. First, having the option of a video teleconference enabled more experts to participate. Second, shifting the prioritization of selected actions to an online survey after the workshops allowed time for reflection and was completed by almost all workshop participants. The Food-EPI tool does not directly capture wider policy action that may address the underlying determinants of health, such as sufficient income to enable healthy food choices, as this is broader than the indicators in the food prices domain which related to food subsidies and taxes rather than income. This research could be complemented by research that investigates public opinion of the proposed policy recommendations with recommendations for other policy actions.

\section{Conclusions}

There has been virtually no progress in New Zealand over the past decade on the implementation of policies and infrastructure support for healthy food environments, with overall regression seen between 2017 and 2020 . While there are some areas where New Zealand is at the level of best practice, almost two thirds of the Food-EPI indicators show major implementation gaps that still need to be addressed. The majority of actions proposed by the expert panel in 2014 were again proposed in 2017 and 2020 due to lack of progress. However, in 2020 the actions recommended were broader, reflecting a growing movement to locate nutrition within the wider context of planetary health and with recognition of the social determinants of health and nutrition. The higher-level actions proposed in 2020 will require the involvement of many government entities. It is important that Food-EPI continues to be conducted every 3 years to monitor government progress and provide a consensus view from public health experts on the most important actions required to prevent obesity and improve diets.

\section{Abbreviations}

Food-EPI: Healthy Food Environment Policy Index; NCD: Noncommunicable disease.

\section{Supplementary Information}

The online version contains supplementary material available at https://doi. org/10.1186/s12961-021-00809-8.

Additional file 1: Healthy Food Environment Policy Index (Food-EPI).

Additional file 2: Recommended actions for the New Zealand government: Policy actions targeting food environments.

\section{Acknowledgements}

The authors would like to thank all the independent and government experts who participated in the Food-EPI process. The authors wish to thank Emily Brownie and Bruce Kidd for their work as research assistants.

\section{Authors' contributions}

SM, SV and BS designed the study. SM, FS and SG collected the data. SM, FS and BS analysed the data. SM wrote the manuscript with major contributions by all authors. All authors read and approved the final manuscript.

\section{Funding}

This project was funded by a project grant from the National Heart Foundation of New Zealand. The funders had no role in study design, data collection and analysis, decision to publish or preparation of the manuscript. 


\section{Availability of data and materials}

The datasets used and/or analysed during the current study are available from the corresponding author on reasonable request.

\section{Declarations}

\section{Ethics approval and consent to participate}

The 2014, 2017 and 2020 studies were approved by the University of Auckland Human Participants Ethics Committee (references 9326, 018605, 023852 respectively). All expert panellist participants provided written consent prior to the workshop after reading an information sheet.

\section{Consent for publication}

Not applicable.

\section{Competing interests}

The authors declare that they have no competing interests.

\section{Author details}

'Department of Epidemiology and Biostatistics, School of Population Health, University of Auckland, Auckland 1023, New Zealand. ${ }^{2}$ Centre for Longitudinal Research He Ara Ki Mua, School of Population Health, University of Auckland, Auckland 1743, New Zealand. ${ }^{3}$ Sciensano (Scientific Institute of Public Health), Epidemiology and Public Health, J.Wytsmanstraat 14, 1050 Brussels, Belgium.

Received: 9 December 2020 Accepted: 16 December 2021

Published online: 15 January 2022

\section{References}

1. Mackay S, Ni Mhurchu C, Swinburn B, Eyles H, Young L, Gontijo de Castro T. State of the Food Supply: New Zealand 2019. University of Auckland 2019.

2. Eyles $\mathrm{H}$, Jiang $\mathrm{Y}$, Blakely T, Neal B, Crowley J, Cleghorn C, et al. Five year trends in the serve size, energy, and sodium contents of New Zealand fast foods: 2012 to 2016. Nutr J. 2018;17(65).

3. Swinburn B, Sacks G, Vandevijvere S, Kumanyika S, Lobstein T, Neal B, et al. INFORMAS (International Network for Food and Obesity/non-communicable diseases Research, Monitoring and Action Support): overview and key principles. Obes Rev. 2013;14(Suppl 1):1-12.

4. Swinburn B, Sacks G, Hall K, McPherson K, Finegood D, Moodie M, et al. The global obesity pandemic: shaped by global drivers and local environments. Lancet. 2011;378(9793):804-14.

5. Vandevijvere S, Chow C, Hall K, Umali E, Swinburn B. Increased food energy supply as a major driver of the obesity epidemic: a global analysis. Bull World Heal Organ. 2015;93(7):446-56.

6. Institute for Health Metrics and Evaluation. Global Burden of Disease: New Zealand. 2017. http://www.healthdata.org/new-zealand.

7. Ministry of Health. Longer, healthier lives: New Zealand's health 1990-2017. Wellington; 2020.

8. OECD. Obesity Update 2017. 2017. https://www.oecd.org/health/obesi ty-update.htm. Accessed 17 May 2020.

9. UNICEF. The State of the World's Children 2019. Children, Food and Nutrition: Growing well in a changing world. New York; 2019.

10. Ministry of Health New Zealand. Annual Update of Key Results 2018/19: New Zealand Health Survey. 2019. https://www.health.govt.nz/publi cation/annual-updatekey-results-2018-19-new-zealand-health-survey. Accessed 20 Mar 2020.

11. Hawkes C, Jewel J, Allen K. A food policy package for healthy diets and the prevention of obesity and diet-related non-communicable diseases: the NOURISHING framework. Bull World Heal Organ. 2015;93(7):446-56.

12. Parsons $K$, Hawkes C. Policy coherence in food systems. In: Rethinking food policy: a fresh approach to policy and practice. London; 2019.

13. Stuckler D, Nestle M. Big food, food systems, and global health. PLoS Med. 2012;9:e1001242.

14. Moodie R, Stuckler D, Monteiro C, Sheron N, Thamarangsi T, Lincoln P, et al. Profits and pandemics: prevention of harmful effects of tobacco, alcohol, and ultra-processed food and drink industries. Lancet. 2013;381:670-9.
15. International Association for the Study of obesity. The prevention of obesity and NCDs: challenges and opportunities for governments. IASO policy briefing. 2014. http://www.iaso.org/site_media/uploads/iaso_ preventingobesitybriefing.pdf.

16. Baker P, Gill T, Friel S, Carey G, Kay A. Generating political priority for regulatory interventions targeting obesity prevention: an Australian case study. Soc Sci Med. 2017;177:141-9.

17. Swinburn B, Vandevijvere S, Kraak V, Sacks G, Snowdon W, Hawkes C, et al. Monitoring and benchmarking government policies and actions to improve the healthiness of food environments: a proposed Government Healthy Food Environment Policy Index. Obes Rev. 2013;14(Suppl 1):24-37.

18. Vandevijvere S, Dominick C, Devi A, Swinburn B. The healthy food environment policy index: findings of an expert panel in New Zealand. Bull World Heal Organ. 2015;93(5):294-302.

19. Vandevijvere S, Swinburn B. Pilot test of the Healthy Food Environment Policy Index (Food-EPI) to increase government actions for creating healthy food environments. BMJ Open. 2015;5(1):e006194.

20. World Health Organization. Global Action Plan for the Prevention and Control of Non-Communicable Diseases 2013-2020. 2013. www.who.int. Accessed 16 Jan 2020.

21. World Health Organization. Consideration of the evidence on childhood obesity for the Commission on Ending Childhood Obesity: report of the ad hoc working group on science and evidence for ending childhood obesity. Geneva; 2016.

22. World Cancer Research Fund. WCRF International Food Policy Framework for Healthy Diets: NOURISHING. http://www.wcrforg/policy_public_affai rs/nourishing_framework/.

23. Brownie E, Sing F, Gerritsen S, Mackay S. Evidence document: Benchmarking NZ Food environment policies against international best practice. Evidence summary for expert panel 2017-2019. University of Auckland; 2020.

24. Vandevijvere S, Mackay S, Swinburn B. Measuring and stimulating progress on implementing widely recommended food environment policies: the New Zealand case study. Heal Res Policy Syst. 2018. https://doi.org/ 10.1186/s12961-018-0278-0.

25. Sing F, Mackay S, Culpin A, Hughes S, Swinburn BA. Food advertising to children in New Zealand: a critical review of the performance of a self-regulatory complaints system using a public health law framework. Nutrients. 2020. https://doi.org/10.3390/nu12051278.

26. Australia and New Zealand Ministerial Forum on Food Regulation. The Australia and New Zealand Ministerial Forum on Food Regulation response to the Health Star Rating System five year review. 2019. https:// foodregulation.gov.au/internet/fr/publishing.nsf/Content/hsr-five-yearreview. Accessed 17 May 2020.

27. Swinburn BA, Kraak VI, Allender S, Atkins VJ, Baker PI, Bogard JR, et al. The global syndemic of obesity, undernutrition, and climate change: the lancet commission report. Lancet. 2019. https://doi.org/10.1016/S01406736(18)32822-8

28. Rush E, Obolonkin V. Food exports and imports of New Zealand in relation to the food-based dietary guidelines. Eur J Clin Nutr. 2020;74(2):307-13.

29. Food Systems Dialogues. Aotearoa Food Systems Dialogues, Summary report. 2020. https://foodsystemsdialogues.org. Accessed 31 Aug 2020.

30. Child Poverty Action Group. Aotearoa, land of the long wide bare cupboard: Food insecurity in New Zealand. 2019. https://www.cpag.org.nz/ campaigns/the-latestaotearoa-land-of-the-long-wide/. Accessed 7 Aug 2020.

31. EAT New Zealand. National Food Strategy. 2020 https://www.eatnewzeal and.nz/national-food-strategy. Accessed 7 Aug 2020.

32. National Food Strategy. National Food Strategy: Part One. 2020. https:// www.nationalfoodstrategy.org/. Accessed 7 Aug 2020.

33. Ministry of Health. Household Food Insecurity among Children: New Zealand Health Survey. Wellington; 2019. https://www.health.govt. nz/publication/household-foodinsecurity-among-children-new-zeala nd-health-survey.

34. Child Poverty Action Group. Aotearoa, land of the long wide bare cupboard. Part 6: Food insecurity in New Zealand. 2020. https://www.cpag. org.nz/assets/12062020CPAG Food Insecurity VI-FINAL.pdf.

35. Child Poverty Reduction Act 2018. 2018 No 57 New Zealand; 2018. 
36. Welfare Expert Advisor Group. Whakamana Tāngata: Restoring dignity to social security in New Zealand. 2019. http://www.weag.govt.nz/ weag-report/.

37. United Nations System Standing Committee on Nutrition. Food environments in the COVID-19 Pandemic. https://www.unscn.org/19?idnews= 2040. Accessed 27 Nov 2020.

38. Ministry of Social Development. Food secure communities FAQs. 2020. https://www.msd.govt.nz/what-we-can-do/community/food-secur ecommunities/faqs.html. Accessed 27 Nov 2020.

39. Gerritsen S, Egli V, Roy R, Haszard J, De BC, Teunissen L, et al. Seven weeks of home-cooked meals: changes to New Zealanders' grocery shopping, cooking and eating during the COVID-19 lockdown. J Roy Soc NZ. 2020. https://doi.org/10.1080/03036758.2020.1841010.

40. Healthier Lives. Call for updated national nutrition survey to see what New Zealanders are eating. 2019. https://healthierlives.co.nz/2019/02/08/ call-for-updated-nationalsurvey/. Accessed 10 Nov 2020.

41. Activity \& Nutrition Aotearoa. Kawea ake te wero: enabling everyone in Aotearoa to eat well. 2020.

42. Swinburn B, Kraak V, Rutter H, Vandevijvere S, Lobstein T, Sacks G, et al. Strengthening of accountability systems to create healthy food environments and reduce global obesity. Lancet. 2015;385(9986):2534-45.

43. Mozaffarian D, Angell SY, Lang T, Rivera JA. Role of government policy in nutrition—barriers to and opportunities for healthier eating. BMJ. 2018. https://doi.org/10.1136/bmj.k2426.

44. Bablani L, Ni Mhurchu C, Neal B, Skeels CL, Staub KE, Blakely T. The impact of voluntary front-of-pack nutrition labelling on packaged food reformulation: a difference-in-differences analysis of the Australasian Health Star Rating scheme. PLOS Med. 2020;17(11):e1003427. https://doi.org/10. 1371/journal.pmed.1003427.

45. Vandevijvere S, Mackay S, D'Souza E, Swinburn B. How healthy are New Zealand food environments? New Zealand: University of Auckland; 2018.

46. Popkin B, Monteiro C, Swinburn B. Overview: Bellagio conference on program and policy options for preventing obesity in the low- and middle-income countries. Obes Rev. 2013;14:1-8.

47. Sacks G. For the Food-EPI Australia Project Team. Policies for tackling obesity and creating healthier food environments 2019 progress update Australian governments. Melbourne; 2019. https://www.foodpolicyindex. org.au/.

48. UK Government. Soft Drinks Industry Levy: detailed information. 2020. https://www.gov.uk/guidance/check-if-your-drink-is-liable-for-the-softdrinksindustry-levy. Accessed 10 Nov 2020.

49. The Food Foundation. Food Environment Policy Index (Food-Epi) for England. UK; 2016.

50. White M, Barquera S. Mexico adopts food warning labels, why now? Heal Syst Reform. 2020;6(1): e1752063. https://doi.org/10.1080/23288604.2020. 1752063.

51. Nieto C, Rodríguez E, Sánchez-Bazán K, Tolentino-Mayo L, CarriedoLutzenkirchen A, Vandevijvere S, et al. The INFORMAS healthy food environment policy index in Mexico: an assessment of implementation gaps and priority recommendations. Obes Rev. 2019;20(S2):67-77. https://doi. org/10.1111/obr.12814.

52. Karbasy K, Vanderlee L, L'Abbé M. Supporting healthier food environments in the City of Greater Sudbury: current policies and actions. Toronto, Canada; 2019. http://labbelab.utoronto.ca/projects/ local-food-epi-2019/.

53. Karbasy K, Vanderlee L, L'Abbé M. Supporting healthier food environments in the Region of Peel: current Policies and priority actions. Toronto, Canada; 2019. http://labbelab.utoronto.ca/projects/local-food-epi-2019/.

54. Karbasy K, Vanderlee L, L'Abbé M. Supporting healthier food environments in the City of Toronto: current policies and priority actions. Toronto, Canada; 2019. http://labbelab.utoronto.ca/projects/local-food-epi-2019/.

55. Kasture A, Vandevijvere S, Robinson E, Sacks G, Swinburn B. Benchmarking the commitments related to population nutrition and obesity prevention of major food companies in New Zealand. Int J Public Heal. 2019;64:1147-57.

\section{Publisher's Note}

Springer Nature remains neutral with regard to jurisdictional claims in published maps and institutional affiliations.

Ready to submit your research? Choose BMC and benefit from:

- fast, convenient online submission

- thorough peer review by experienced researchers in your field

- rapid publication on acceptance

- support for research data, including large and complex data types

- gold Open Access which fosters wider collaboration and increased citations

- maximum visibility for your research: over 100M website views per year

At BMC, research is always in progress.

Learn more biomedcentral.com/submissions 